\title{
Vaginal Cancer cM0 TNM Finding v7
}

National Cancer Institute

\section{Source}

National Cancer Institute. Vaginal Cancer cMO TNM Finding v7. NCI Thesaurus. Code C89474.

Vaginal cancer without evidence of distant metastasis. (from AJCC 7th Ed.) 